\title{
Pattern of chronic urticaria in SohagUniversity Hospitals
}

\author{
Reham E. Elsharkawi ${ }^{1}$, Sahar A.AbdElwahed ${ }^{2}$,Wafaa M.Abd Elmaged ${ }^{1}$ and \\ Doaa A.A. Abd Elgaber ${ }^{1}$. \\ ${ }^{1}$ Departement of Dermatology, Venereology and Andrology, Faculty of Medicine, Sohag \\ University. \\ ${ }^{2}$ Departement of Clinical Pathology, Faculty of Medicine, Sohag University.
}

\begin{abstract}
Background:Chronic urticaria $(\mathrm{CU})$ is a skin disorder characterized by the recurrent appearance of wheals and/or angioedema for at least 6 weeks. CU is a heterogeneous disorder which includes chronic spontaneous urticaria (CSU) and chronic inducible urticaria (CIU).

Objective:To study the pattern of chronic urticaria among the patients attending dermatology outpatient clinic in Sohag University Hospitals and to study the association between the results of autologous serum skin test (ASST) and urticaria severity score (USS)and to detect serum level of anti IgE receptors antibodies using ELISA.

Results:ASST was positive in $41(38 \%)$ patients andthere was a statistically significant relation between ASST result and duration of the disease ( $p$ value 0.014).22 (20.4\%) of the patients had mild score , 50 (46.3\%) had moderate score and $36(33.3 \%)$ had severe score. The relation of USS to the positivity of ASST was statistically significant ( $\mathrm{p}$ value 0.000 ). The mean of anti IgE receptor antibodies in ASST positive group was more than that of those negative ones that was highly statistically significant ( $\mathrm{P}$ value 0.000 ).

Conclusion:ASST remains a baseline diagnostic test for CAU. Patients with CAU had more frequent attacks and longer duration than other types of chronic urticaria.
\end{abstract}

\section{Introduction}

Chronic urticaria is a skin disorder characterized by transient pruritic wheals that recur from day to day for 6 weeks or more (1). Females are affected nearly twice as often as males, and that the peak age of manifestation of CU is 20-40 years (2). The incidence of CU has been estimated at $1.4 \%$ per year in USA (3). The current European Academy of Allergy and Clinical Immunology (EAACI), Global Allergy and Asthma European Network (GA2LEN), European Dermatology Forum (EDF) and World Allergy Organization (WAO) guidelines for urticaria recommend that chronic urticaria is then divided into its two primary subgroups according to whether symptoms occur spontaneously ( chronic spontaneous urticaria ) or are induced by a demonstrable stimulus ( chronic inducible urticaria) (4).

\section{1) Chronic inducible urticaria:}

Inducible CU is defined when a trigger for $\mathrm{CU}$ can be identified. There are many types including, symptomatic dermographism, cold urticaria, cholinergic urticaria, delayed pressure urticaria, solar urticaria, vibratory

urticaria, aquagenicurticaria and contact urticaria(5).

\section{2) Chronic spontaneous urticaria:}

It refers to CU in which appearance of lesions is not triggered by consistent or identifiable factors, and it specifically excludes the physical urticaria syndromes (6).It accounts for approximately two-thirds of all cases of chronic urticaria(7).CSU is classified into 2 major subtypes including chronic autoreactive urticaria 
and chronic idiopathic urticaria(8). a-Autoreactive chronic urticaria $\underline{\text { (ACU): }}$

Autoreactive chronic urticaria (ACU) is considered to be the most severe form of chronic urticaria(9). About $50 \%$ of the cases of chronic urticaria are considered autoreactive diseases, due to the presence of circulating histamine-releasing autoantibodies, especially directed against IgE highaffinity receptors (FcERI $\alpha$ ) present in the cytoplasmic membrane of mast cells and basophils or anti-IgE autoantibodies(10).

b-Chronic idiopathic urticaria (CIU):

Chronic idiopathic urticaria (CIU) isdefined as the occurrence of daily, or almost daily, wheals and itching for at least 6 weeks, with no obvious cause (11).Patients with chronic idiopathic urticaria do not have evidence of autoimmunity. In this form of urticaria, there appears to be persistent activation of mast cells, but the mechanism of mast cell triggering is unknown (12).

Several etiologic factors have been associated with CU throughout history: thyroid diseases, pseudo-allergens, actual allergens, Helicobacter pylori infection, other infections/infestations and autoimmunity/ autoreactivity(10).

\section{Diagnosis of chronic urticaria:}

It is necessary to obtain a thorough history, including all possible eliciting factors, and to identify the significant aspects of the disease. These parameters are as follows: age of patients at presentation, age of patients at onset of urticaria, urticaria severity score, duration of the disease in months, duration of each wheal in hours, frequency of attacks per week, distribution of wheals, interference of the disease with daily activities, presence of angioedema, interference of the disease with sleep, presence of family history of chronic urticaria, presence of personal and/or family history of atopy, and presence of personal and/or family history of autoimmune diseases and medications (NSAIDs, hormones, laxatives, immunizations); and observed correlation with food and stress(13).

Physical examinationshould include identifying and characterizing any current lesions, testing for dermatographism (hives induced by rubbing intact skin), and checking for signs of systemic illness(including recurrent fever, weight loss, and joint symptoms) (14). Routine hematological tests, including complete blood count , liver function tests, renal function tests, the determination of erythrocyte sedimentation rate, and C-reactive protein levels may be considered. Testing for Helicobacter pylori. Screening for thyroid autoimmunity by T3, T4 and TSH level, stools for parasites and urine analysis. When history suggests a physical urticaria, challenge testingwith physical stimuli may be considered.TheASSTis the only generally available test to screen for auto-antibodies against either $\operatorname{IgE}$ or the high-affinity IgEreceptor (15).

\section{2- Aim of the work:}

The aim of this study is to:

1- Study the pattern of chronic urticaria among the patients attending dermatology outpatient clinic in Sohag University Hospitals. 2- And to study the association between the results of autologous serum skin test (ASST) and urticaria severity score (USS). 3-And to detect serum level of anti $\operatorname{IgE}$ receptors antibodies using ELISA.

\section{3-Patients and methods:}

This study included patients complaining of chronic urticaria (those having recurrent episodes of wheals with or without angiodema of at least 6 weaks ) who attended Dermatology Outpatient Clinic at Sohag University Hospitals from April 2015 to March 2016. The study was submitted for approval by Research and Ethical 
committees at Faculty of Medicine, Sohag University. A written informed consent was taken from each patient.The inclusion criteria was all cases of chronic urticaria, both sexes, those aged from 15-70 years old.The exclusion criteria was pregnant and lactating women, those aged less than 15 and more than 70 years old, patients complaining of angioedema without wheals and urticarial vasculitis.

\section{Table(I):Urticaria severity score (13)}

The study was submitted for approval by Research and Ethical committees at Faculty of Medicine, Sohag University. A written informed consent was taken from each patient. Urticarial severity was assessed for each patient using urticaria severity score. The severity score was divided into three groups: mild (less or equal 5), moderate (6-10), and severe ( more than10)(13).

\begin{tabular}{|c|c|}
\hline \multicolumn{1}{|c|}{ Parameter } & Score \\
\hline $\begin{array}{c}\text { Frequency of attacks: } \\
\text { (Days per week) }\end{array}$ & \\
\hline $1-2$ days & 1 \\
\hline $3-5$ days & 2 \\
\hline$>5$ days & 3 \\
\hline Duration of each wheal: & 1 \\
\hline$<1$ hour & 2 \\
\hline 6-6 hours & 3 \\
\hline Distribution of wheals: & \\
\hline Face and extremities & 1 \\
\hline All over the body & 2 \\
\hline Interference with sleep: & \\
\hline No & 0 \\
\hline Yes & 2 \\
\hline Interference with activities: & \\
\hline No & 0 \\
\hline Annoying & 1 \\
\hline Abstinence from work & 2 \\
\hline Associated angioedema: & \\
\hline Eyelids, lips, or hands & 2 \\
\hline Any 2 of above & 3 \\
\hline All of them & \\
\hline
\end{tabular}

Autologous serum skin test (ASST) was done. Patients had to be off antihistamines for at least 3 days (longacting antihistamines for 7 days) and corticosteroids and other immunosuppressive drugs for 4 weeks before the study to reduce the possibility of generating false-negative results (15).

Samples of $5 \mathrm{ml}$ of venous blood were collected in sterile plain tube without a clotting accelerator and allowed to clot at room temperature for $30 \mathrm{~min}$. After centrifugation at $2000 \mathrm{rpm}$ for $15 \mathrm{~min}$, Samples of $0.05 \mathrm{ml}$ of autologous serum and $0.9 \%$ sterile normal saline were separately injected intradermally into the volar aspect of the right forearm with a gap of $5 \mathrm{~cm}$ between injection sites. Wheal and flare response was measured at $30 \mathrm{~min}$. ASST was documented to be positive if a serum-induced wheal which was both red and had a diameter bigger 
than a saline-induced response by $\geq 1.5$ $\mathrm{mm}$ was seen at $30 \mathrm{~min}(\mathbf{1 6})$.

To confirm the autoreactivity of chronic urticaria, serum level of anti immunoglobulin E receptor antibody were assessed using ELISA method. Using Anti IgE receptor antibody kit allowing for the in vitro quantitative determination of anti-IgE receptor antibody concentrations in serum of the patients.

\section{Statistical analysis:}

Data was analyzed using SPSS computer program version 16.0. Qualitative data were presented as numbers and percentages. Quantitative data were expressed as means \pm standard deviation, median and range. The data were tested for normality using Kolmogrov-Smirnov test and Shapiro-Wilk test which were significant indicating the use of non parametric tests as data wasn't normally distributed. Chi-square $\left(\chi^{2}\right)$ test was used for comparison regarding qualitative variables. The non parametric Mann-Whitney test was used for comparing two quantitative variables. Kruskal-Wallis test was used for comparison between more than two quantitative variables.

\section{Results}

\section{Autologous serum skin test (ASST):}

As regard ASST, it was positive in 41 (38\%) patients and negative in $67(62 \%)$ as shown in table 1 and figure 1 . There was a statistically significant relation between ASST result and duration of the disease ( $p$ value 0.014).But no statistically significant relation between ASST and age of the patients or the type of chronic urticaria ( $\mathrm{p}$ value $0.403,0.081$ ) respectively .

Table 1: The autologous serum skin test (ASST) in the study group

\begin{tabular}{|c|c|c|}
\hline The autologous serum skin test (ASST) & No. & \% \\
\hline \hline Negative & 67 & 62.0 \\
\hline Positive & 41 & 38.0 \\
\hline \hline Total & 108 & 100.0 \\
\hline
\end{tabular}

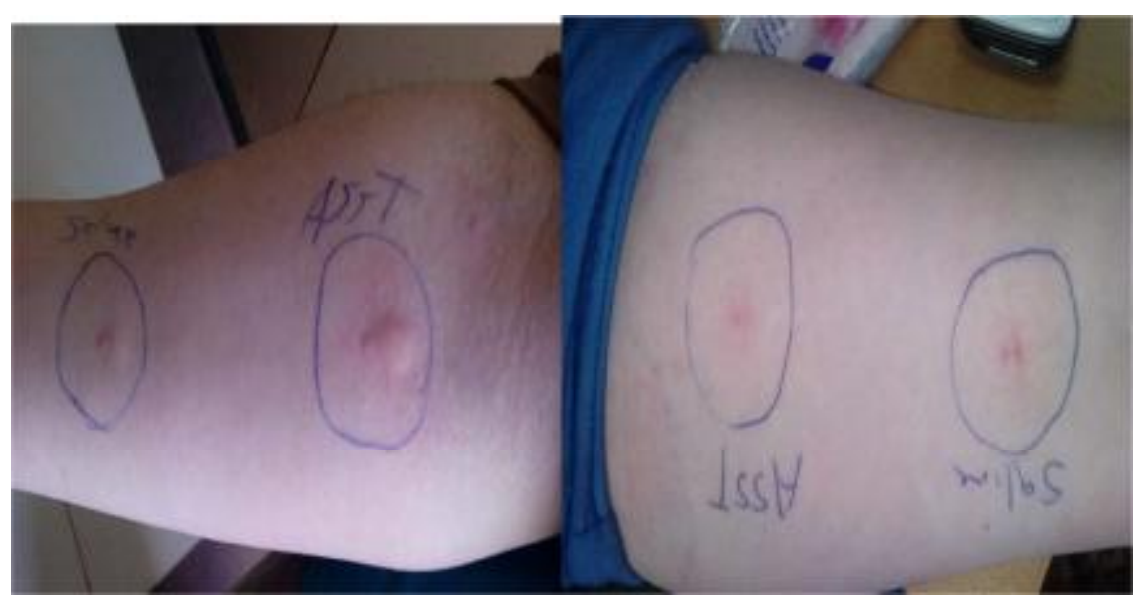

(a)

(b)

Figure 1: (a) Positive ASST, (b) Negative ASST. 


\section{Urticaria severity score (USS):}

In our study, $22(20.4 \%)$ of the patients had mild score , $50(46.3 \%)$ had moderate score and $36(33.3 \%)$ had severe score. The relation of USS to the positivity of ASST was statistically significant ( $\mathrm{p}$ value 0.000 ) as shown in table 2.

Table 2: The relation of ASST to each score group $(N=108)$

\begin{tabular}{||c||c||c||c||}
\hline The score & $\begin{array}{c}\text { Positive ASST } \\
\text { No. (\%) }\end{array}$ & $\begin{array}{c}\text { Negative ASST } \\
\text { No. (\%) }\end{array}$ & $\begin{array}{c}\text { Total } \\
\text { No. (\%) }\end{array}$ \\
\hline \hline$\leq \mathbf{5}$ (mild) & $0(0)$ & $22(100)$ & $22(100.0)$ \\
\hline $\begin{array}{c}\mathbf{6} \text { to 10 } \\
\text { (moderate) }\end{array}$ & $12(24)$ & $38(76)$ & $50(100.0)$ \\
\hline \hline$>\mathbf{1 0}$ (severe) & $29(80.6)$ & $7(19.4)$ & $36(100.0)$ \\
\hline \hline Total & $41(38)$ & $67(62)$ & $108(100.0)$ \\
\hline \hline \multicolumn{1}{|c|}{$\chi^{\mathbf{2}=\mathbf{4 5 . 3 3}}$} & $\mathbf{P = 0 . 0 0 0 *}$ & \\
\hline
\end{tabular}

\section{P- value was calculated by Chi square test.}

\section{Serum level of anti IgEreceptor antibodies:}

The normal detection range of anti IgE receptor antibodies in the serum is $7 \mathrm{ng} /$ ml- $200 \mathrm{ng} / \mathrm{ml}$. In the present study, those antibodies were searched for in 83 patients .Thirty three $(39.8 \%)$ of those patients had positive antibodies but $50(60.2 \%)$ had negative ones. Thirty $(90.9 \%)$ patients of the antibody positive patients had positive ASST that was statistically significant (p value 0.000 ) as shown in table 3 . The overall mean $\pm(\mathrm{SD})$ of anti $\mathrm{IgE}$ receptor antibodies in ASST positive and negative patients were $28.72 \pm(43.62), 2.79 \pm(1.19) \mathrm{ng} / \mathrm{ml}$ respectively. The mean of anti $\mathrm{IgE}$ receptor antibodies in ASST positive group was more than that of those negative ones that was highly statistically significant ( $\mathrm{P}$ value 0.000 ).

Table 3:Anti IgE receptor antibodies in positive and negative ASST patients (N. =83).

\begin{tabular}{||c|c|c|c||}
\hline Anti IgE R antibodies & $\begin{array}{c}\text { Positive ASST } \\
\text { No. }(\%)\end{array}$ & $\begin{array}{c}\text { Negative ASST } \\
\text { No. }(\%)\end{array}$ & $\begin{array}{c}\text { Total } \\
\text { No. }(\%)\end{array}$ \\
\hline Positive anti IgE R antibody & $30(90.9)$ & $3(9.1)$ & $33(39.8)$ \\
\hline Negative anti IgE R antibody & $11(22)$ & $39(78)$ & $50(60.2)$ \\
\hline Total & $41(49.4)$ & $42(50.6)$ & $83(100.0)$ \\
\hline \hline \multicolumn{2}{|c|}{$\mathbf{P = 0 . 0 0 0}$} \\
\hline
\end{tabular}

P- value was calculated by Mann-Whitney test.

\section{Discussion}

Chronic urticaria (CU) is a skin disorder characterized by the recurrent appearance of wheals and/or angioedema for at least 6 weeks. CU is a heterogeneous disorder and includes chronic spontaneous urticaria (CSU) and chronic inducible urticaria (CIU) (17).Chronic autoreactive urticaria is a distinct subgroup of $\mathrm{CU}$ where its recognition 
has facilitated better understanding of persistent chronic spontaneous urticaria. These patients have autoantibodies against alpha chain of $\mathrm{IgE}$ receptors of mast cells and basophils (18).

Our study included 108 patients complaining of chronic urticaria. They represented $1.13 \%$ of the total of patients who attended dermatology clinic at Sohag University Hospitals from april 2015 to march 2016. Eighty five $(78.7 \%)$ patients were females and the male to female ratio is $1: 3.7$.The reasons for this sex-related differences are not completely understood. A possible explanation may be the autoimmune nature of the disease, at least in a subgroup of patients with CSU (19). The present study showed that mean of duration of chronic urticaria is $3.1 \pm 3.87$ years. This is in consistant with another study (15). In contrast to another study (20)in which the mean duration of complaint ranged from 1.5 months up to 10 years. This means that duration of chronic urticaria varies widely among different populations and from person to another in the same population.

Sixty three of the patients $(58.3 \%)$ in this study complained of CSU, seven $(6.5 \%)$ of the patients complained of physical urticaria and $38(35.2 \%)$ complained of mixed type of chronic urticaria. In another study (21), the percentages were $23.3 \%, 27.4 \%$, $40.3 \%$ respectively.Ten percent of the patients in this study had an urticarial wheal concomitantly with atopic symptoms .These were suspected of being an IgE-mediated mechanism. Previous studies (22)revealed little evidence to suggest that allergy is an important factor in CU. However, allergy is more important in acute urticaria than chronic urticaria.

Various infections have been reported to be the associating factors of $\mathrm{CU}$ including parasitic infection, hepatitis and H. pyroli infection. In this study, $6.5 \%$ of the patients were positive for helicobacter pylori antigen, This is in contrast to a previous study (23)in which $70.5 \%$ of patients were positive for this finding. Such different results could be explained by differences in the antigenicity or biological activity of the bacteria (HP) in different areas, with different socio-economic and genetical patterns of the host population(24).

In the current study, five $(4.7 \%)$ of the patients had thyroid disease .(25)reported higher percent of thyroid problems in their study (9.8\%). Both indicates the association of chronic urticaria to thyroid disease. This may explain the coexistence of autoantibodies in both (anti-thyroid peroxidase antibodies and $\mathrm{IgE}$ receptor antibodies) because of B-cell hyperreactivity.Drugs account for a minority of chronic urticaria. However, it is common to see exacerbation of chronic urticaria caused by medication (26). In our study urticarial wheals and symptoms were exacerbated in $32.4 \%$ of the patients following the intake of non steroidal anti-inflammatory drugs (NSAID). This is coincidient withprevious study (27). This could be due to a direct action of these drugs on mast cell degranulation as a result of inhibition of the cyclo-oxygenase pathway, which causes enhanced production of leukotrienes.

In our study, USS showed that 22 $(20.4 \%)$ of the patients had mild score , $50(46.3 \%)$ had moderate score and 36 (33.3\%) had severe score. These results are near to the results ofprevious study(28)and in contrast to another one(13). Those different results may be due to different in severity of chronic urticaria among different people.

In this study the frequency of ASST positive patients among patients with CU was $38 \%$. Those was in 
compatable with previous study(29). Subsequent studies (30) and(31) reported that prevalence of ASST positivity in patients of chronic urticaria varies from $34 \%$ to $67 \%$. Those are a subset of patients with CU who have functional antibodies against the high affinity IgE receptor, or less commonly IgE.The prevalence difference according to the ethnic group of population suggests a genetic background for the disease (15).There was a highly statistically significant relation between severity of USS and positivity of ASST indicating that chronic autoreactive urticaria patients have more severe symptoms that could not be controlled easily. This agrees with studies (32) and (31) and in contrast to other studies(13) and (19).

Serum anti $\operatorname{IgE}$ receptor antibody level was significantly higher in ASST positive group in which $90.9 \%$ of the positive antibodies patients were having positive ASST. There was a highly statistically significant relation between those antibodies and their mean $\pm \mathrm{SD}$ to the positive ASST patients $(\mathrm{P}=0.000)$. This explains the autoimmune nature. It is not affected by age of the patients, type or duration of chronic urticaria. In other studies(33)and (21)there was a significant relation between elevated total IgE levels and patients with positive ASST.

\section{6- Summary and conclusion:}

In conclusion, Chronicurticaria is not uncommon disease. It has high incidence in females. Its severity varies according to its type. The autoimmune type is the most severe one and the longer in duration where ASST can indicate it in a high degree.

\section{7- Recommendation:}

Larger community based studies are needed to detect prevalence of chronic urticaria in populations, serum $\operatorname{IgE}$ level is needed to be assessed in all patients with chronic urticaria, thyroid anti-microsomal and anti-peroxidase antibodies should be assessed in CU patients and larger studies with application of autohemotherapy are needed for patients with positive ASST.

\section{References}

1.Ferrer M. and Kaplan AP. Progress and Challenges in the Understanding of Chronic Urticaria. Allergy, Asthma, and Clinical Immunology 2007; 3 (1): 31-35.

2.Losol P., Yoo HS. and Park HM. Molecular Genetic Mechanisms of Chronic Urticaria. Allergy, Asthma \& Immunology Research $2014 ; 6$ (1) :1321.

3.Bernstein JA., Lang DM.and Khan DA. The diagnosis and management of acute and chronic urticaria: 2014 update. Journal of Allergy and Clinical Immunology.2014; 133: 1270-1277.

4.Maurer M., Bindslev- Jensen C., Gimenez-Arnau A., Godse K., Grattan C.E.M., Hide M. and Kaplan A.P. Chronic idiopathic urticaria (CIU) is no longer idiopathic: time for an update. British Association of Dermatologists 2013;168 (2) :455-456.

5.Khan DA. Chronic urticaria: Diagnosis and management . Allergy Asthma 2008; 29: $439-446$.

6.Saini S.S..Chronic Spontaneous Urticaria Etiology and Pathogenesis.Immunology and allergy clinics of North America. 2014; 34 : 33-52.

7. Weller K., Maurer M. Grattan C., Nakonechna A., Arnau MA. andFrutos JO . ASSURE-CSU: a real-world study of burden of disease in patients with symptomatic chronic spontaneous urticaria. Clinical and Translational Allergy 2015; 5:29.

8.Kaplan AP. Treatment of Chronic Spontaneous Urticaria. Allergy, Asthma \& Immunology Research 2012 ;4 (6) :326-331. 
9.Mlyneka A., Maurerb M., and Zalewska A. Update on chronic urticaria: focusing on mechanisms. Current Opinion in Allergy and Clinical Immunology 2008, 8:433-437.

10.Criado PR., Criado RF., Maruta CW. and Silva VM. Chronic urticaria in adults: state-of-the-art in the new millennium. An Bras Dermatol. 2015; 90 (1): 74-89.

11.Greaves MW. Chronic idiopathic urticaria. Current Opinion in Allergy and Clinical Immunology 2003; 3 (5) :363-8.

12.Kanani A., Schellenberg R. and Warrington R. Urticaria and angioedema. Allergy, Asthma \& Clinical Immunology 2011; 7 (1) : S9.

13.Al-Hamamy HR., Hameed AF.andAbdulhadi AS. Autologous Serum Skin Test as a Diagnostic Aid in Chronic Idiopathic Urticaria.ISRN Dermatology 2013.

14.Ben-Shoshan M. ,Blinderman I. andRaz A. Psychosocial factors and chronic spontaneous urticaria: asystematic review. European Journal of allergy and Clinical Immunology 2013; 68: 131-141.

15.Sanchez-Borges M., Asero R., Ansotegui IJ., Baiardini I., Bernstein JA., Walter Canonica G., Gower R., and Kahn DA. Diagnosis and Treatment of Urticaria and Angioedema: A Worldwide Perspective. World Allergy Organization 2012; 5:125-147.

16.George M., Balachandran C., Prabhu S. Chronic idiopathic urticaria: comparison of clinical features with positive autologous serum skin test. Indian journal of dermatology 2008;74 (2) :105-8.

17.Al-Ahmad M., Alowayesh MS. And Carroll NV.Economic burden of refractory chronic spontaneous urticaria on Kuwait's health system.Clinicoecon Outcomes Res. 2016; 8: 163-169.
18.Inamadar AC. And Palit A. Management of autoimmune urticaria. Indian Journal of Dermatology, Venereology and Leprology 2008; 74 (2): 89-91.

19.Lapi F., Cassano N., Pegoraro V., Cataldo N., Heiman F., Cricelli I., Levi M., Colombo D., Zagni E., Cricelli C. and Vena GA.Epidemiology of chronic spontaneous urticaria: results from anationwide, population-based study in Italy.British Journal of Dermatology 2016; 174 (5) : 996-1004.

20.Heng JK., KohLJ., Paul ST. and Wee DCA.A study of treatment adherence and quality of life among adults with chronic urticaria in Singapore.Asia Pac Allergy 2015; 5 (4) : 197-202 .

21.Ue AP., Souza PK., Rotta O., Furlani WJ. , Lima AR. and Sabbag DS. Quality of life assessment in patients with chronic urticaria. Journal Brazilian Annals of Dermatology 2011; 86 (5) :897-904..

22.Vichayanond $P$, Sunthornchart $S$, Singhivannusorn V. Prevalence of asthma, allergic rhinitis and eczema among university students in Bangkok. Resp Medicine 2002; 96: 34-38.

23.Yadav MK., Rishi JP., Nijawan S. Chronic urticaria and Helicobacter pylori. Indian Journal of Medical Sciences 2008; 62:157-62.

24.Moreiraa A., Rodriguesa J., Delgadoa L., Fonsecaa J. andVaza M. Is Helicobacter pylori infection associated with chronic idiopathic urticaria?.Allergologia et Immunopathologia 2003;31 (4) :20914.

25.Confino-Cohen R., Chodick G., Shalev V., Leshno M., Kimhi O. and Goldberg A. Chronic urticaria and autoimmunity: Associations found in alarge population study. Journal of Allergy Clinical Immunology 2012; 129: 1307-13.

26.Kulthanan K., Jiamton S., Thumpimukvatana N. and Pinkaew S. Chronic idiopathic urticaria: prevalence and clinical course. International 
Journal of Dermatology 2007 ;34 (5) :294-301.

27.Sussman G., Hebert J. , Gulliver W., Lynde C., Waserman S., Kanani A., Ben-Shoshan M. and Horemans S. Insights and advances in chronic urticaria: a Canadian perspective. Allergy, Asthma and Clinical Immunology 2015; 11:7.

28.ToubiE., KesselA., AvshovichN. , BambergerE., SaboE., Nusem D. and Panasoff J.Clinical and laboratory parameters in predicting chronic urticaria duration: a prospective study of 139 patients.Allergy 2004: 59: 869873.

29.Asero R., Tedeschi A., Lorini M., Salimbeni R., Zanoletti T. and Miadonna A.Chronic urticaria: novel clinical and serological aspects. ClinExp Allergy. 2001; 31 (7) :110510.

30.Nettis E, Dambra P, D'Oronzio L, Cavallo E, Loria MP, Fanelli M, et al. Reactivity to autologous serum skin test and clinical features in chronic idiopathic urticaria. Journal of Clinical
\& Experimental Dermatology Research 2002; 27: 2931.

31.Caproni M, Volpi W, Giomi B, Cardinali C, Antiga E, Melani L. Chronic idiopathic and chronic autoimmune urticaria: Clinical and immunopathological features of 68 subjects. ActaDermato-Venereologica 2004; 84: 288 - 290.

32.Sabroe R.A., Poon E., Orchard GE., Lane D., Francis DM., Barr RM., Black MM., Black AK., and Greaves MW. Cutaneous inflammatory cell infiltrate in chronic idiopathic urticaria: Comparison of patients with and without anti-FceRI or anti-IgE autoantibodies. Journal of Allergy and Clinical Immunology 1999; 103(3):484-493.

33.Kessel A., Helou W., Bamberger E., Sabo E., Nusem D., Panassof J. and Toubi E.Elevated serum total IgE--a potential marker for severe chronic urticaria.International Archives of Allergy and Immunology 2010; 153 (3) :288-93. 